\title{
Syringe suction drain further simplified
}

Dear Sir,

Closed suction drainage is a well accepted method of drainage. Its role in preventing postoperative seroma, hematoma, wound dehiscence and infection is well known. The syringe suction drain system can be 


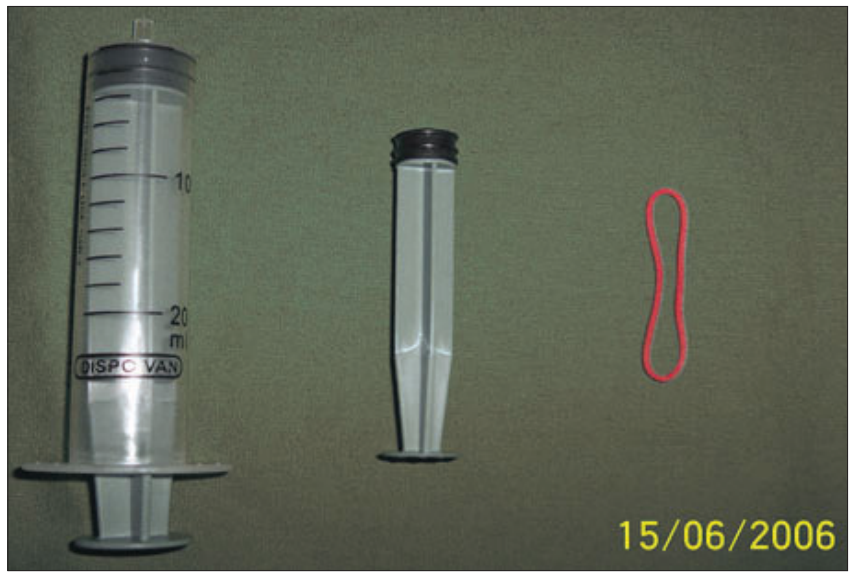

Figure 1: The Syringe Suction device comprises of a $20 \mathrm{cc}$ syringe, a $5 \mathrm{cc}$ syringe piston and a rubberband

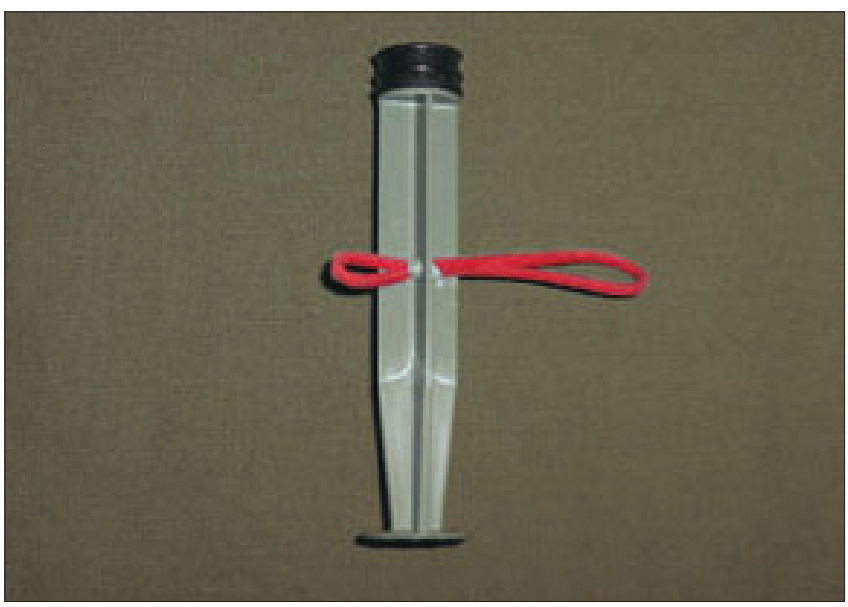

Figure 2: The rubber band is passed through a hole in the $5 \mathrm{cc}$ piston to form small loop and a big loop

effectively used in small wounds. It utilizes the readily available resources in the operation theatre. This article presents a simplified method to recharge the suction device.

A 20cc syringe, a 5cc syringe piston and a rubber band is required to assemble the system [Figure 1]. Sterile rubber bands are readily available in our operation theatre as they are used to pack the sterile gauze pieces.

When a suction drain is deemed necessary in a small wound we close the wound over a No. 8 infant feeding tube, which then receives the syringe suction assembly, thereby functioning as a closed suction drain. A hole is made in the piston of the $5 \mathrm{cc}$ syringe using a hollow bore needle followed by a towel clip. A rubber band is then passed into the hole to form a smaller and a bigger loop [Figure 2]. The smaller loop is then looped

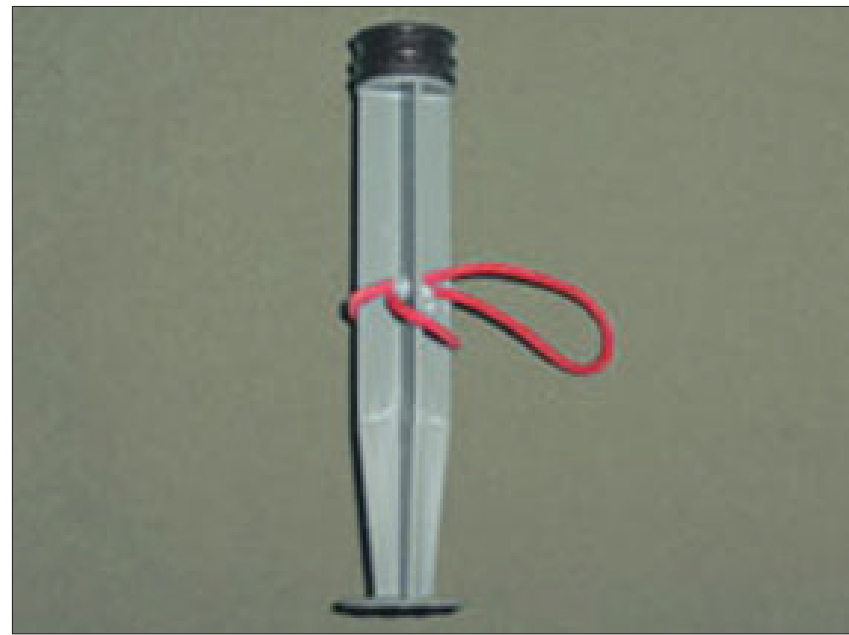

Figure 3: The small loop is looped around the $5 \mathrm{cc}$ piston

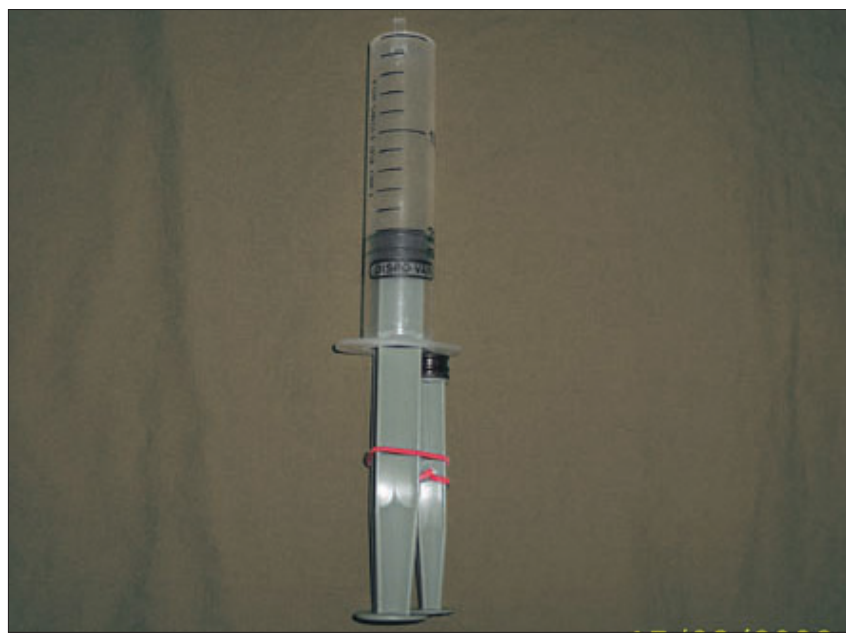

Figure 4: The big loop is used to anchor the $5 \mathrm{cc}$ piston as a stopper

around the piston of the $5 \mathrm{cc}$ syringe [Figure 3]. The 20cc syringe may then be connected to the infant feeding tube, negative suction applied and maintained using the $5 c c$ syringe rubber band assembly as a stopper between the end of the 20cc piston and the end of the body of the 20cc syringe. The two pistons are then secured by looping the bigger rubber band loop around the $20 \mathrm{cc}$ piston [Figure 4].

This method simplifies the process of recharging the closed suction drainage system.

By using a rubber band incorporated into the system the process of recharging is less cumbersome and simplified as compared with a plaster used by Park et al[ ${ }^{[1]}$ and Gopal et al. ${ }^{[2]}$ This method is safer than using a $\mathrm{k}$ wire or a large bore needle passed transversely through the $5 \mathrm{cc}$ piston as a stopper. ${ }^{[3]}$ A spring used instead of a $5 \mathrm{cc}$ piston as described 
by Singh et $a l^{[4]}$ would appear to be a better system but requires a specialized spring for the purpose.

\section{Sunderraj Ellur}

Department of Plastic and Reconstructive Surgery, St. Johns Medical College, Bangalore, India

Address for correspondence: Dr. Sunderraj Ellur, Department of Plastic and Reconstructive Surgery, St Johns Medical College Hospital, Bangalore - 560 034, Karnataka, India. E-mail: sundernetra@yahoo.co.in

\section{REFERENCES}

1. Park DH, Song CH, Han DG, Ahn KY, Byun JS. A simple negative suction drain for ear reconstruction. Plast Reconstr Surg 1999;103:972-5.

2. Gopal SV, Kumar M. A simple negative suction drainage for small surgical wounds. Indian J Surg 2005;67:282-3.

3. Singh A, Singh G. Syringe Suction drain II. Br J Plast Surg 2003;56:313.

4. Singh A, Thind MS, Mander KS, Singh GP. Syringe suction drain. Br J Plast Surg 1992;45:484-5. 